\title{
Design, development and biomechanical evaluation of a prefabricated anti pronation foot orthosis
}

\author{
Rachel Majumdar, Philip Laxton, Anna Thuesen, Christopher Nester*, Barry Richards \\ From 3rd Congress of the International Foot and Ankle Biomechanics Community \\ Sydney, Australia. 11-13 April 2012
}

\section{Background}

Custom made foot orthoses remain the 'gold standard' because the orthotic geometry is tailored to each patient's foot. However, due to their reduced cost, in some contexts there has been an increasing preference for prefabricated orthoses. Research has failed to identify major differences between the two types of orthosis [1-4]. This project aimed to design, develop and evaluate a new anti-pronation foot orthosis. The project was initiated following observations that many prefabricated orthoses failed to incorporate the design principles used in custom made orthoses and the lack of evidence for the effect of prefabricated orthoses on foot pronation.

\section{Materials and method}

The project comprised three stages. In stage 1 (definition of problem) professional, patient, consumer and retail opinions of existing foot orthoses was sought through

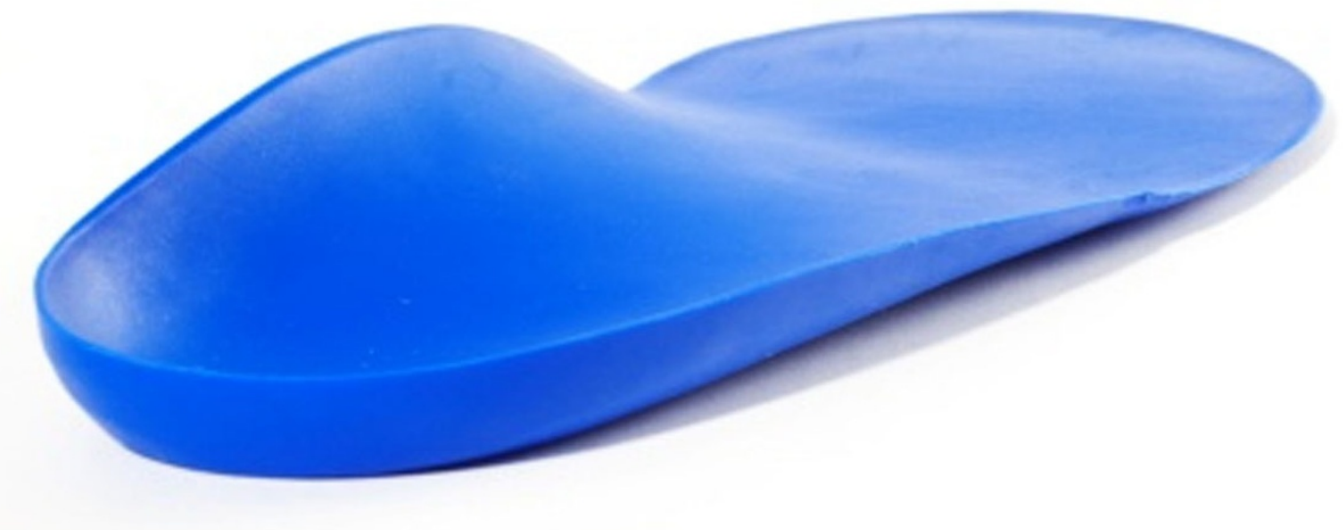

Figure 1 Final orthotic and cross section of arch geometry

\footnotetext{
* Correspondence: c.j.nester@salford.ac.uk

Centre for Health Sciences Research, University of Salford, Salford, M6 6PU,
} UK 


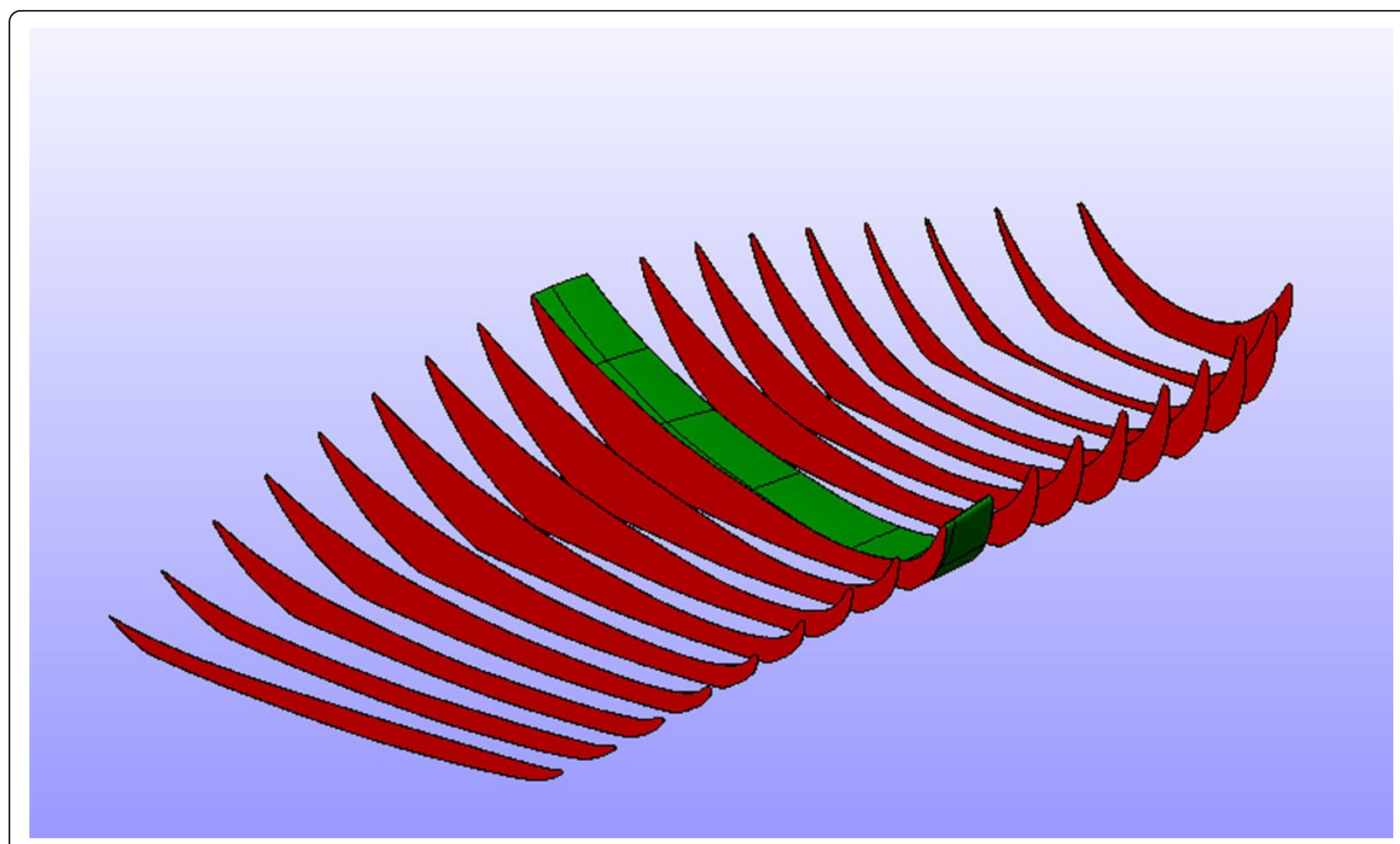

Figure 2 Final orthotic and cross section of arch geometry

unstructured interviews. This produced a technical specification for the new orthosis. In stage 2 (development of orthosis), 80 foot casts were rationalised through observation of cast shape and testing of prototype orthoses to identify a 'model' foot shape. Bespoke orthotic materials were formulated and tested to compare durability and stiffness to existing orthosis materials. In stage 3 (evaluation), rearfoot inversion/eversion was measured in 30 people walking and running, in a standard shoe, with and without the orthosis. Marker triads were attached to the heel via a shoe aperture, and to the leg.

\section{Results}

The orthotic is illustrated in Figure $1 \& 2$. Maximum rearfoot eversion was reduced (Figure 3 and 4 ) in both walking (reduced by $3.4^{\circ}, \mathrm{SD} 3.5^{\circ}$ ) and running (by $2.2^{\circ}$,

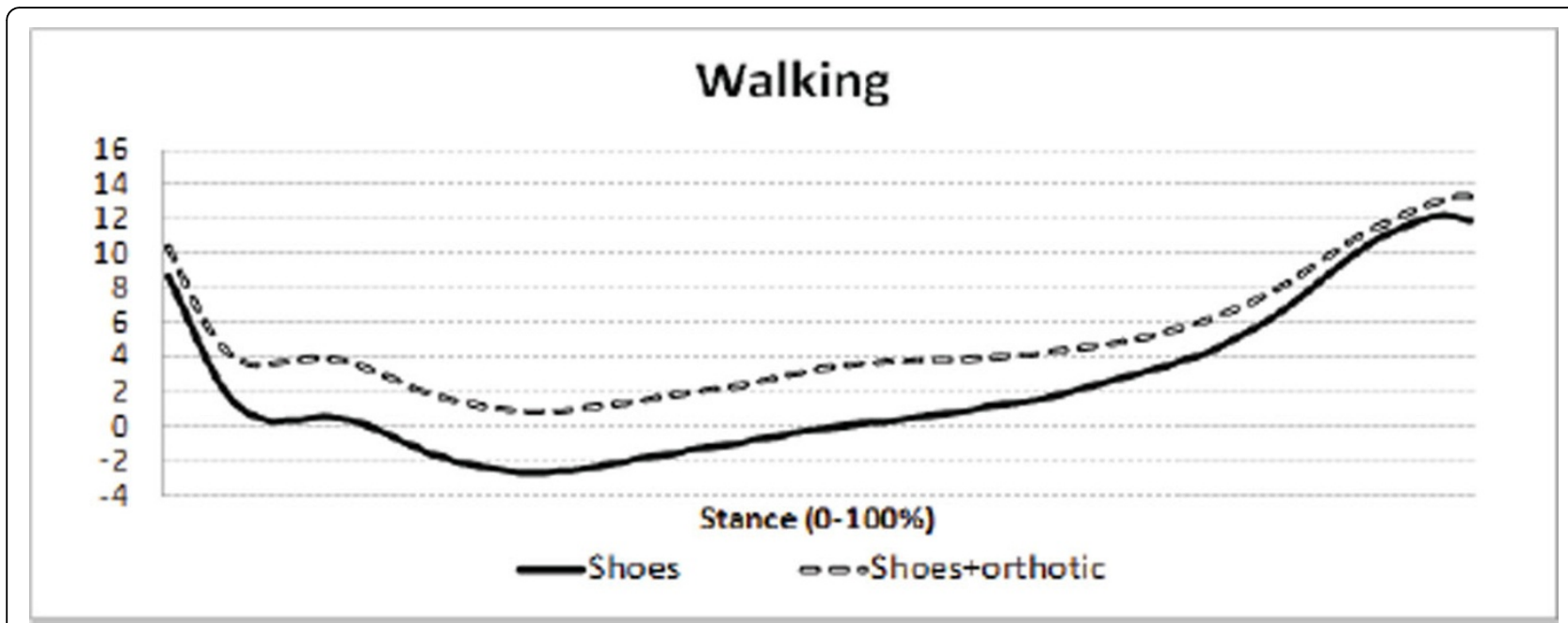

Figure 3 Rearfoot inversion $\left(+v^{\circ}\right)$ and eversion (-ve $)$ during walking and running with and without the orthotic. $0^{\circ}=$ relaxed standing 


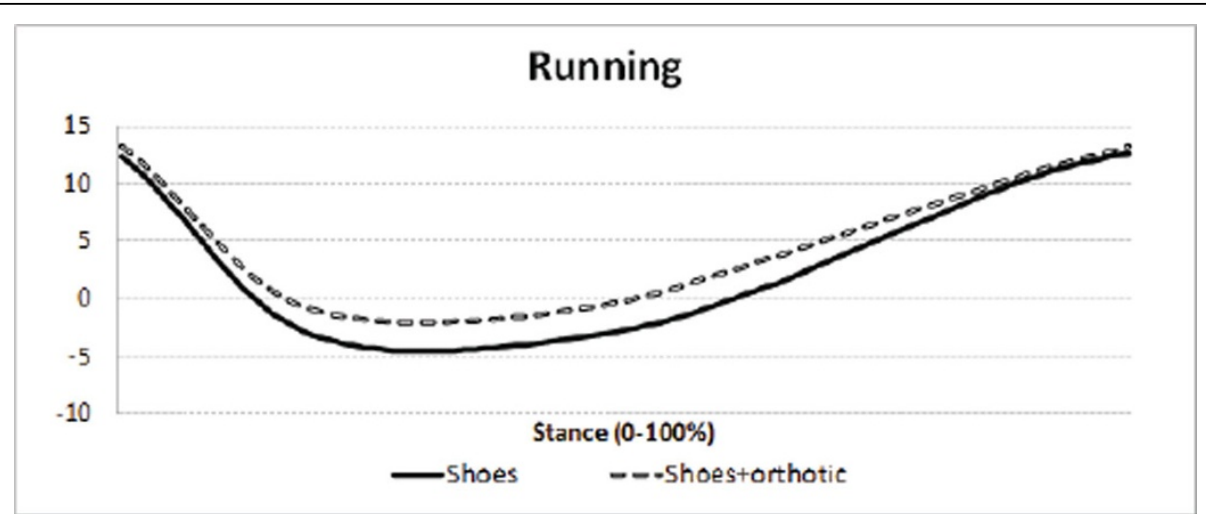

Figure 4 Rearfoot inversion $\left(+v^{\circ}\right)$ and eversion $\left(-v e^{\circ}\right)$ during walking and running with and without the orthotic. $0^{\circ}=$ relaxed standing

$\left.\mathrm{SD} 2.8^{\circ}\right)(\mathrm{p}<0.001)$. The walking reduction is larger than reported by Mills $\left(2.12^{\circ}\right)$ [5] following meta analysis of the literature, but like other reports the orthotic effect was highly person specific.

\section{Conclusion}

The project produced a foot orthosis with evidence of: its design and development process; its material properties compared to existing orthotic materials; its effect on foot pronation.

\section{Acknowledgements}

This work was funded under the UK Government "Knowledge Transfer Partnership" scheme, supporting transfer of knowledge from Universities to industry.

Published: 10 April 2012

\section{References}

1. Murley GS, Landorf KB, Menz HB: Do foot orthoses change lower limb muscle activity in flat-arched feet towards a pattern observed in normalarched feet? Clin Biomech 2010, 25:728-36.

2. Baldassin V, Gomes CR, Beraldo PS: Effectiveness of prefabricated and customized foot orthoses made from low-cost foam for noncomplicated plantar fasciitis: a randomized controlled trial. Arch Phys Med Rehabil 2009, 90:701-706.

3. Redmond AC, Landorf KB, Keenan AM: Contoured, prefabricated foot orthoses demonstrate comparable mechanical properties to contoured, customised foot orthoses: a plantar pressure study. J Foot Ankle Res 2009, 16:2-20.

4. Landorf KB, Keenan AM, Herbert RD: Effectiveness of foot orthoses to treat plantar fasciitis: a randomized trial. Arch Intern Med 2006. 166:1305-1310.

5. Mills K, Blanch P, Chapman AR, McPoil TG, Vicenzino B: Foot orthoses and gait: a systematic review and meta-analysis of literature pertaining to potential mechanisms. Br J Sports Med 2010, 44:1035-1046.

doi:10.1186/1757-1146-5-S1-P22

Cite this article as: Majumdar et al:: Design, development and biomechanical evaluation of a prefabricated anti pronation foot orthosis. Journal of Foot and Ankle Research 2012 5(Suppl 1):P22.

\section{Submit your next manuscript to BioMed Central} and take full advantage of:

- Convenient online submission

- Thorough peer review

- No space constraints or color figure charges

- Immediate publication on acceptance

- Inclusion in PubMed, CAS, Scopus and Google Scholar

- Research which is freely available for redistribution

Submit your manuscript at www.biomedcentral.com/submit 